\title{
СУЩНОСТЬ ПОНЯТИЯ «ЧЕЛОВЕЧЕСКИЙ КАПИТАЛ», ПРИМЕНИТЕЛЬНО К ОБРАЗОВАТЕЛЬНОЙ ОРГАНИЗАЦИИ
}

\author{
(c) 2021 Зотова Елизавета Александровна \\ старший преподаватель, Высшая школа производственного менеджмента \\ Санкт-Петербургский политехнический университет Петра Великого, Россия, Санкт-Петербург \\ E-mail: zotova@spbstu.ru
}

На сегодняшний день процесс цифровой трансформации мировой экономики определил совокупность качественных изменений практически всех аспектов жизнедеятельности человека. Значимой трансформации подверглась сфера высшего образования. Данное утверждение в первую очередь проявляется в снижении барьеров профессионального взаимодействия, что в свою очередь значительно повышает вариативность формирования научно-исследовательских коллективов. Именно научно-исследовательские коллективы выступают основой формирования человеческого капитала образовательной организации в условиях цифровой трансформации. В данной статье представлены результаты исследования по уточнению понятия «человеческий капитал», применительно к образовательной организации в условиях цифровой трансформации.

Ключевые слова: человеческий капитал, образовательная организация, организация высшего образования, синергия.

Устойчивое развитие экономики России в рамках цифровой трансформации возможно только при активном внедрении инновационных разработок в реальный сектор экономики, сокращение времени на решение вопросов административного характера и при наличии высококвалифицированных кадров, способных решать сложные задачи в условиях неопределенности. Решения поставленных задач могут быть выработаны в рамках высших учебных заведений, имеющих высокий инновационный потенциал и человеческий капитал. Инновационные университеты обладают достаточно высоким человеческим капиталом, обладают инструментами и необходимой материально-технической базой для коммерциализации инновационных продуктов в реальный сектор экономики. В связи с этим, эффективное управление человеческим капиталом в рамках высших учебных заведений окажет положительные экстерналии как на реальный сектор экономики путем вывода на рынок коммерчески успешные инновационные разработки, так и на сферу управления, путем создания и трансформации моделей и методик управления человеческим капиталом, что позволит наиболее эффективно использовать ресурсы организации и повысить их конкурентоспособность, в том числе и на международном рынке.

При этом, проводя анализ сферы высшего

образования стоит отметить, что выпускникам университетов для построения успешной карьеры уже недостаточно базовых знаний, им необходимы компетенции по решению нетривиальных задач в условиях цифровой трансформации, соответственно для того чтобы университет успешно реализовывал подготовку востребованных высококвалифицированных кадров и генерировал инновационные разработки с высоким потенциалом коммерциализации, университету необходим высокий уровень человеческого капитала как в административном аппарате, так и в научных школах и профессорскопреподавательском составе. Для более глубокого понимания термина «человеческий капитал» рассмотрим его с точки зрения отечественного и зарубежного подхода к терминологическому аппарату.

В современной экономической системе человеческий капитал является основным ресурсом как на макро, так и на микроуровне. От уровня человеческого капитала зависит производительность труда, эффективность использования основных активов, успех применения инновационных технологий и в целом успех организации.

Дефиницию «человеческий капитал» ввел Нобелевский лауреат по экономике Г.С.Беккер в своей книге «Человеческий капитал», объясняя появление данного термина необходимостью 
оценки трудового потенциала предприятия и возможности его повышения, т.е. эффективность предприятия будет зависеть не только от наличия современного оборудования, эффективного управления, но и от квалификации и мотивации работников. Особо подчеркивается необходимость инвестировать в человеческий капитал для повышения прибыльности организации [1].

На основе развития экономической мысли появляются модели, основанные на интеллектуальных ресурсах в рамках человеческого капитала, так в 80-х годах XX столетия. Э.Долан и Дж.Линдсей характеризуют человеческий капитал как совокупность интеллектуальных способностей человека, инвестирование в которые позволяют получать больше прибыли [2].

Ведущими отечественными учеными, занимающиеся разработкой и совершенствованием теории человеческого капитала являются: М.М.Критский, Л.И.Абалкин, Ю.С.Емельянов, И.В.Ильинский, О.В.Калинина, С.А.Дятлов, Д.Г.Родионов, Ю.А. Корчагина, В.В.Глухов, Т.Л.Судова, Б.В.Корнейчук, И.В.Скоблякова, А. И. Добрынин, С. А. Курганский, В. Т. Смирнов и др.

Одним из первых отечественных ученых выделявшим человеческий капитал как экономическую категорию был М.М.Критский. Он считал, что человеческий капитал - одновременно универсальная и в тоже время уникальная форма деятельности человека, которая включает в себя производственный, потребительский и интеллектуальный капитал [3].

Симкина Л.Г увязывает понятие человеческого капитала с инновационными преобразованиями в экономике, при этом, отмечает важность человеческого капитала для общественного потребления [4].

Акцент на мотивацию и инвестиции в человеческий капитал делает академик Л.И. Абалкин, который предлагает под человеческим капиталом понимать совокупность различных характеристик человека, таких как образование, опыт работы, творческий потенциал, здоровье человека (как физическое состояние, так и психологическое) [5]. Автор отмечает важность инвестиций в человеческий капитал путем получения высшего образования, профессиональной переподготовки, повышения квалификации и т.д.

Более широкое определение человеческого капитала предложено СулеймановойЛ.Ш., ко- торая характеризует человеческий капитал не только совокупностью характеристик человека, которые образовались в результате инвестиций, но и отмечает прямое влияние человеческого капитала на уровень доходов человека на микроуровне и развитие экономики страны на макроуровне [6].

Далее рассмотрим перечень авторов, характеризующих человеческий капитал как совокупность характеристик человека, позволяющие их владельцу получать доход. Так, Климов С. М. формирует понятие человеческого капитала как комплекс характеристик, имеющихся у человека с рождения и приобретенных в процессе жизнедеятельности, который используется для получения дохода [7].

Определение человеческого капитала как совокупности природных характеристик человека, которые он в процессе обучения совершенствует и успешно применяет для выполнения рабочих обязанностей, что приводит к повышению производительности труда,- формулирует Корогодин И.Т [8].

Б.Г.Юдин [9] и Б.М.Генкин [10] отмечают важную особенность человеческого капитала как накопление и формулируя свои определения человеческого капитала делают упор на характеристики человеческого потенциала, который успешно применяется в деятельности человека по получению дохода. Базируясь на данном подходе Гришнова О.А. [11] определяет человеческий капитал, в первую очередь, как экономическую категорию, характеризующую качества человека, сформированные в результате инвестиций, а также его мотивацию, позволяющие как получать доход владельцу человеческого капитала за счет более высокой производительности труда, так и повышать уровень благосостояния населения в целом. К рассмотренными выше авторам выделяющих экономическую сущность человеческого капитала стоит отнести Базилевича В.Д., который формулирует определение человеческого капитала как способность личности использовать накопленные способности для обеспечения дохода [12]. В более широком понимании рассматривает человеческий капитал ШевчукЛ. Т. [13]: ресурсы общества в целом, позволяющие генерировать добавленную стоимость, т.е. человеческий капитал - комплекс знаний, умений, навыков и компетенций общества, используемые для производства товаров и услуг. 
Физиологические аспекты дефиниции человеческий капитал отмечает ряд авторов, так Добрынин А.И. определяет человеческий капитал как совокупность знаний, умений и навыков, базирующихся на факторе здоровья человека [14]. По мнению автора, формируемый человеческий капитал за счет инвестиционных вложений позволяет увеличить производительность труда и доход владельца человеческого капитала. Поддерживает социальный аспект понятия человеческий капитал Корчагин Ю.А., который считает, что существует прямая зависимость уровня жизни населения от инвестиций в человеческий капитал, при этом, автор уточняет, что человеческий капитал является необходимым составляющим для создания интеллектуальной собственности, инновационных разработок, формирования инновационного потенциала, предпринимательского климата, а также культуpe, искусстве и здоровье населения [15].

И.В.Ильинский рассматривает понятие человеческий капитал как совокупность трех основных аспектов: образовательного, культурного и физиологического, при этом так же как и многие ученые отмечает необходимость инвестирования в здоровье, что, по мнению автора, будет позволять повышать уровень производительности труда человека и, как следствие, его уровень благосостояния [4]. Важность здоровья как основной составляющей человеческого капитала отмечает Синицына Г.И. в своей работе, посвященной региональному аспекту человеческого капитала она выявила зависимость уровень человеческого капитала в регионе от качества здоровья населения [16]. При этом, так же дифференцирует человеческий капитал на три основных составляющие: биологическую, как базовую для накопления человеческого капитала, и социальную, как развитие человеческого капитала путем теоретического и практического обучения, и экономическую, как использование накопленного человеческого капитала для получения дохода.

В.Щетинин отмечает большое количество существующих подходов к определению человеческий капитал. Так в узком понимании человеческий капитал можно охарактеризовать как знания, умения и навыки, полученные в ходе образовательной деятельности. В широком понимании автор выделяет так же социальную и физиологическую компоненты. При этом, отмечает, что на формирование человеческого капи- тала основное влияние оказывают инвестиции, а отличительной особенностью человеческого капитала является ее гибкость, т.е. способность капитала как к быстрому приращению, так и снижению [17].

Что касается современных иностранных авторов, то рассмотрим работы, направленные на совершенствование методологической базы дефиниции «человеческий капитал». Рана Эйджаз Ахмад в своей работе «Значение человеческого капитала» [18] определяет человеческий капитал как совокупность характеристик, таких как: образование, обучение, миграция, опыт, процесс политических исследований, здравоохранение и т.д. Значение человеческого капитала для экономического роста во многом связано с формой культуры любой страны.

Густаво Перейра Серра в работе «Формирование человеческого капитала» [19] рассматривает человеческий капитал с точки зрения инвестиций для ускорения научно-технологического процесса. При этом автор отмечает, что накопление человеческого капитала не является источником экономического роста, а может сдерживать динамику роста в долгосрочной перспективе.

Социальный подход к определению человеческого капитала использует Блэр Фикс [20]. Анализируя теоретические подходы сквозь историческую призму, автор отмечает, что накопление человеческого капитала делает людей более продуктивными. Соответственно с течением времени человеческий капитал может как накапливаться и повышать конкурентоспособность личности, так и иметь обратную направленность, т.е. с течением времени совокупный человеческий капитал организации может снижаться.

Марк Бантинг рассматривает человеческий капитал как совокупность навыков, образования и способностей человека. Соответственно, эти способности человека позволяют генерировать денежные средства. Так же автор вводит понятие «риск человеческого капитала» и интерпретирует его как комплекс факторов, влияющих на снижение уровня человеческого капитала в определенной области [21].

Агус Маулана рассматривает теорию человеческого капитала, в которой отмечает, что человеческие ресурсы больше не являются производственными факторами, функции которых приравниваются к машинам, при этом активно 
исследуются социальные факторы, в которых активным образом вкладываются инвестиции. Люди становятся самым важным активом в организациях, их человеческий капитал повышается путем проведения тренингов в рамках hard и soft skills [22].

Таким образом, подводя итог проведенному теоретическому исследованию дефиниции «человеческий капитал» составим сводную таблицу выделяя изменения в подходах к определению «человеческий капитал» (рисунок 1).

Условно можно выделить четыре исторических периода развития подходов к определению «человеческий капитал»: середина XX века, середина - конец XX века, конец XX века - начало XXI века, первая четверть XXI века. Понятие «человеческий капитал» с течением времени трансформировалось от экономической категории к социально-экономической, содержащей три основные компоненты: образовательную, культурную и физиологическую. При этом базовой компонентой принято считать физиологическую, так как здоровье человека будет основой для повышения квалификации человека, его культурного роста и т.д. Соответственно можно условно выделить основные подходы к определению человеческого капитала (рисунок 2).

Авторов, которые определяют человеческий капитал как совокупность физиологической и образовательной компонент, можно условно вы- делить в экономическую категорию, т.е. авторы отмечают важность инвестирования в здоровье человека и его образование для того чтобы повысить эффективность их работы и, как следствие, производительность труда организации в целом.

Другими авторами отмечается важность учета социальных эффектов от повышения уровня человеческого капитала, отмечается важность не только инвестирования в физиологические и образовательные компоненты, но и выделяется культурная компонента, которая отмечается как необходимая часть управления персоналом в организации и создания рабочего климата.

Перспективным подходом к определению человеческий капитал является рассмотрение его как отдельной самостоятельной категории, которая рассматривается как важнейшая часть организации. При этом, авторами данного подхода отмечается невозможность нахождения уровня человеческого капитала в состоянии покоя, он постоянно трансформируется либо в сторону приращения, либо сокращается.

Таким образом, проведенное теоретическое исследование позволяет сделать вывод о том, что в настоящее время нет единого подхода к понятию человеческий капитал, при этом в условиях цифровой трансформации имеющиеся подходы имеют некоторые ограничения. В первую очередь это связано со стремительным прираще-

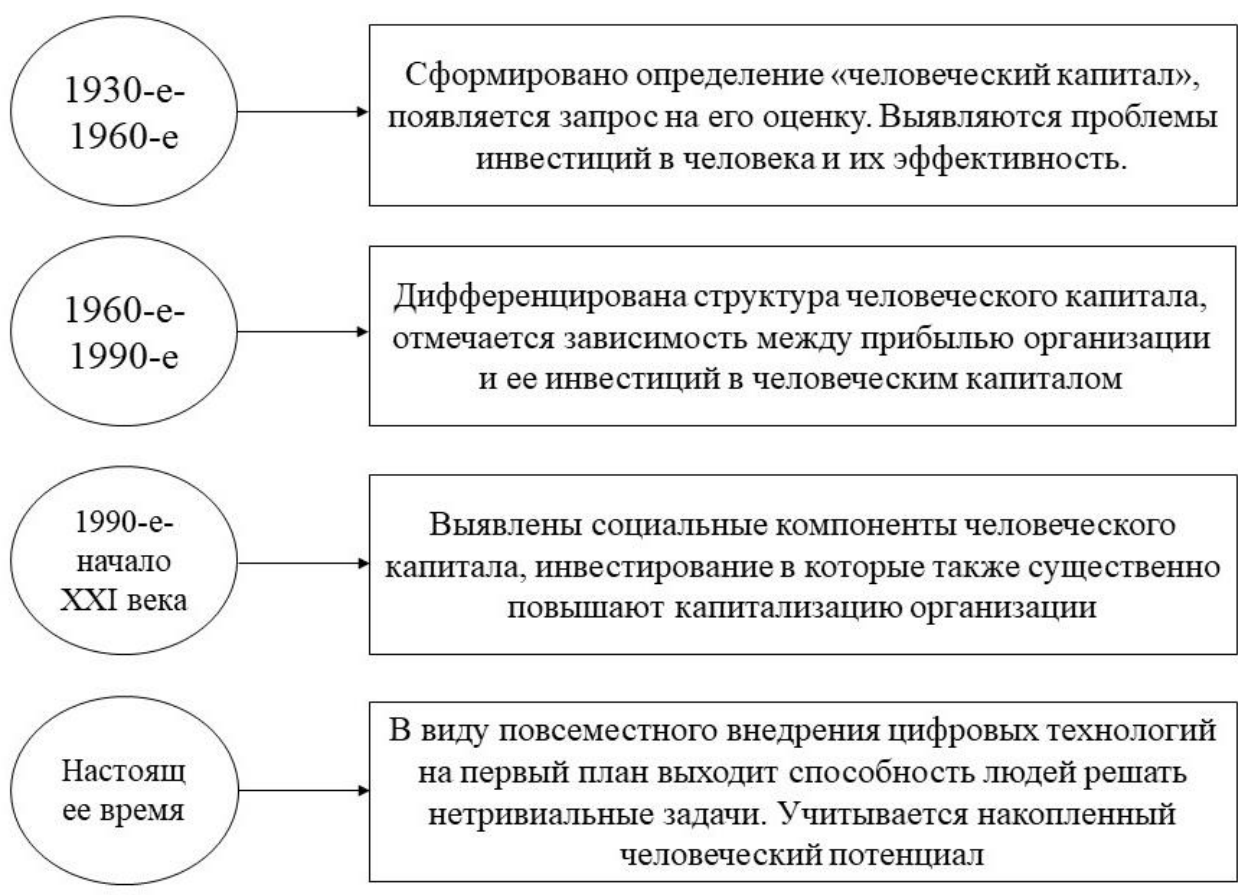

Рисунок 1. Историческая ретроспектива определения «человеческий капитал» 


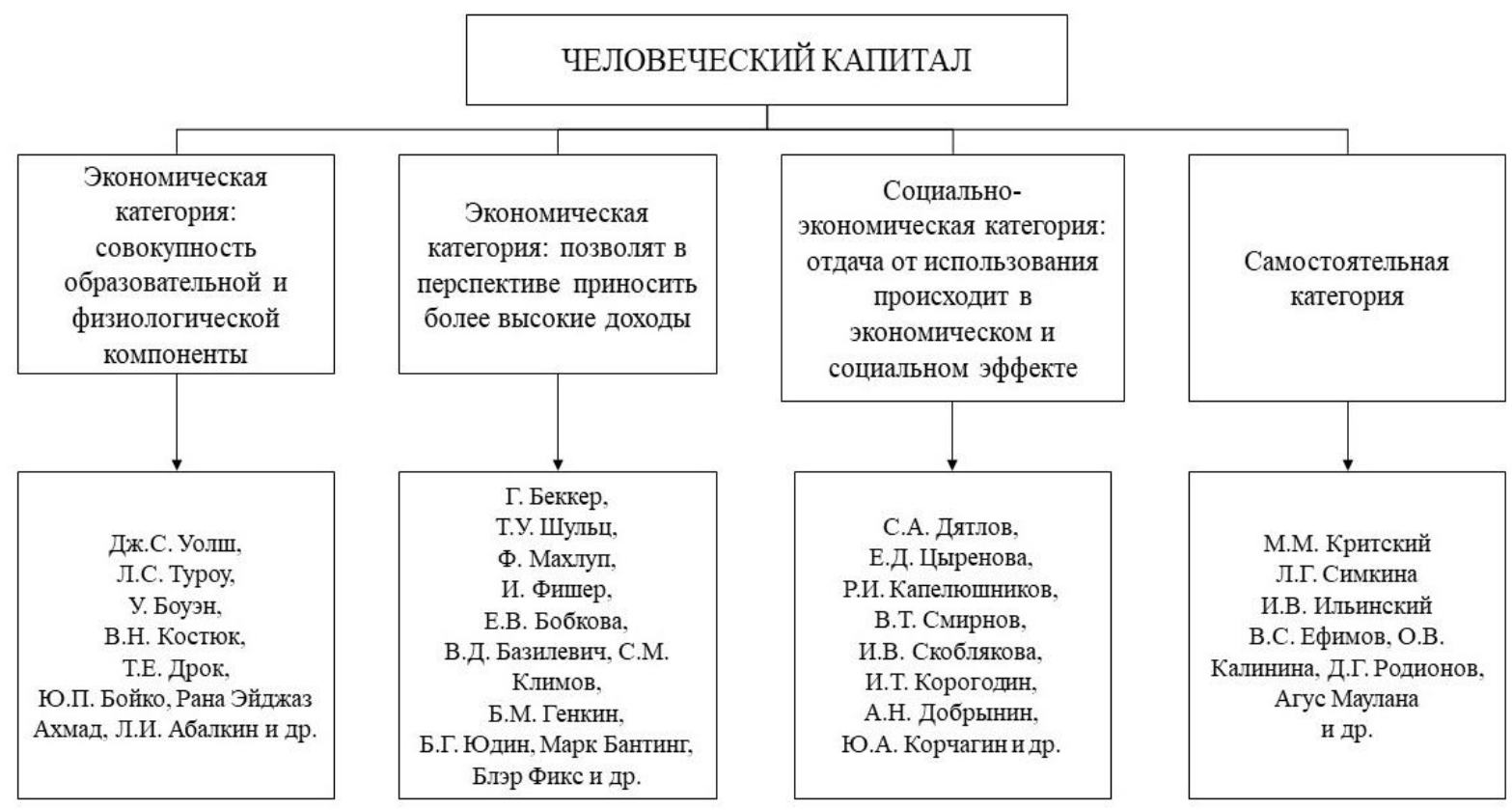

Рисунок 2. Основные подходы к понятию человеческий капитал

нием использования информационных технологий как в производственных предприятиях, так и в организациях. Особенно это касается сферы образования, где внедрение информационных технологий осуществляется значительно быстрее чем в других отраслях, соответственно профессорско-преподавательский состав вынужден проходить повышение квалификации или переподготовку по цифровой грамотности. Вместе с тем, накопленный человеческий капитал в условиях цифровой трансформации может быть существенно снижен и требовать существенной замены в виду нового технологического уклада. В связи с этим, необходимо сформулировать определение человеческого капитала, имеющего отраслевую специфику в условиях цифровой трансформации.

Основной гипотезой для генерации уточненного категориального аппарата служит то, что человеческий капитал является комплексом компетенций человека, т.е. образовательной компонентой, его физического состояния, т.е. физиологической компонентой и культурной компонентой, которая включает в себя способность человека взаимодействовать с коллегами, способность использовать свои компетенции в конкретном коллективе, а также чувствовать себя частью компании. Исходя из выделенных компонент следует отметить, что они находятся в постоянном движении, т.е. качество тех или иных качеств человека постоянно изменяются в большую или меньшую сторону. Вместе с тем уровень человеческого капитала накапливается не линейно и с каждой новой компетенцией человек может кратно увеличивать свой человеческий капитал, что говорит о синергии компетенций в рамках личности. Таким образом, сформулируем определение человеческий капитал в условиях цифровой трансформации.

Человеческий капитал - комплекс физиологической, образовательной и культурной компонент, формируемых с учетом синергетического эффекта, используемый для эффективного управления высшими учебными заведениями в условиях цифровой трансформации.

Особенностью сформулированного определения является то, что человеческий капитал в условиях активного внедрения информационных технологий в образовательный, управленческий, организационный процессы является основным ресурсом высшего учебного заведения для повышения своей конкурентоспособности. При этом, отмечается важная особенность человеческого капитала как синергия, т.е. каждая новая компетенция работника высшего учебного заведения может кратно повышать его человеческий капитал, соответственно повышать эффективность его работы и, как следствие, повышает конкурентоспособность высшего учебного заведения. Построим на основе предложенной гипотезы методику формирования человеческого капитала (таблица 1). Сформулируем формулу 
нахождения человеческого капитала:

$$
\text { ЧК }=\sum\left(a_{n} * k_{1}\right)\left(b_{n} * k_{2}\right)\left(c_{n} * k_{3}\right)
$$

Где:

1. a, b, с - компоненты человеческого капитала.

2. $\mathrm{k}$ - удельный вес компоненты (сумма удельных весов по отдельной группе компонент равна 1).

Интерпретируем формулу: человеческий капитал является совокупностью компонент, каждая из которых имеет свою степень важности, соответственно человеческий капитал будет не только суммой всех компонент человека, а будет суммой произведений различных компонент, за счет чего будет достигаться синергетический эффект, который существенно усиливается в условиях цифровой трансформации.

Несмотря на отраслевую специфику сформулированного определения оно имеет универсальный характер, так совокупность имеющихся компетенций у работников может быть совершенно различно и дифференцировано с учетом весовых коэффициентов, которые в свою очередь можно определить при помощи закона Фишберна [23]. В связи с этим в определении не выделяются конкретные компетенции, а предложены лишь группы компонент. Соответственно, набор компетенций работника может трансформироваться в зависимости от сферы деятельности организации, при этом синергетический эффект также будет достигаться за счет эффективной коллаборации компетенций в рамках конкретного работника.

Таким образом, в результате проведенного исследования было выявлено, что человеческий капитал осуществляет свое приращения на основании синергии компетенций, при этом в условиях инновационного развития высшего учебного заведения человеческий капитал из одного из ключевых ресурсов трансформируется в основополагающий интеллектуальный ресурс, осуществляющий управление высшим учебным заведением. Соответственно, в условиях активного внедрения инновационных технологий существующие подходы к управлению инновационного развития высшим учебным заведением требуют существенных изменений.

Таблица 1. Методика формирования человеческого капитала

\begin{tabular}{|c|c|c|c|}
\hline № & Наименование компоненты & Важность компоненты & Совокупность компонент \\
\hline & Физиологическая & & \\
\hline 1 & $\mathrm{a}_{1}$ & $\mathrm{k}_{1 \mathrm{i}}$ & $\mathrm{a}_{1} * \mathrm{k}_{1 \mathrm{i}}$ \\
\hline 2 & $\mathrm{a}_{2}$ & $\mathrm{k}_{1 \mathrm{j}}$ & $\mathrm{a}_{2} * \mathrm{k}_{1 \mathrm{j}}$ \\
\hline 3 & $\mathrm{a}_{3}$ & $\mathrm{k}_{1 \mathrm{~m}}$ & $\mathrm{a}_{3} * \mathrm{k}_{1 \mathrm{~m}}$ \\
\hline \multirow[t]{3}{*}{$\ldots$} & $a_{n-1}$ & $\mathrm{k}_{1 \mathrm{n}-1}$ & $\mathrm{a}_{\mathrm{n}-1} * \mathrm{k}_{1 \mathrm{n}-1}$ \\
\hline & & $\sum \mathrm{k}_{1}=1$ & $\sum \mathrm{a}_{\mathrm{n}} * \mathrm{k}_{1}$ \\
\hline & Образовательная & & \\
\hline 1 & $\mathrm{~b}_{1}$ & $\mathrm{k}_{2 \mathrm{i}}$ & $\mathrm{b}_{1} * \mathrm{k}_{2 \mathrm{i}}$ \\
\hline 2 & $\mathrm{~b}_{2}$ & $\mathrm{k}_{2 \mathrm{j}}$ & $\mathrm{b}_{2} * \mathrm{k}_{2 \mathrm{j}}$ \\
\hline 3 & $\mathrm{~b}_{3}$ & $\mathrm{k}_{2 \mathrm{~m}}$ & $\mathrm{~b}_{3} * \mathrm{k}_{2 \mathrm{~m}}$ \\
\hline \multirow[t]{3}{*}{$\ldots$} & $b_{n-1}$ & $\mathrm{k}_{2 \mathrm{n}-1}$ & $\mathrm{~b}_{\mathrm{n}-1} * \mathrm{k}_{2 \mathrm{n}-1}$ \\
\hline & & $\sum \mathrm{k}_{2}=1$ & $\sum \mathrm{b}_{\mathrm{n}} * \mathrm{k}_{2}$ \\
\hline & Культурная & & \\
\hline 1 & $\mathrm{c}_{1}$ & $\mathrm{k}_{3 \mathrm{i}}$ & $\mathrm{c}_{1} * \mathrm{k}_{3 \mathrm{i}}$ \\
\hline 2 & $\mathrm{c}_{2}$ & $\mathrm{k}_{3 j}$ & $\mathrm{c}_{2} * \mathrm{k}_{3 \mathrm{j}}$ \\
\hline 3 & $\mathrm{C}_{3}$ & $\mathrm{k}_{3 \mathrm{~m}}$ & $\mathrm{c}_{3} * \mathrm{k}_{3 \mathrm{~m}}$ \\
\hline \multirow[t]{2}{*}{$\ldots$} & $c_{n-1}$ & $\mathrm{~K}_{3 n-1}$ & $\mathrm{c}_{\mathrm{n}-1} * \mathrm{k}_{3 \mathrm{n}-1}$ \\
\hline & & $\sum \mathrm{k}_{3}=1$ & $\sum \mathrm{c}_{\mathrm{n}}{ }^{*} \mathrm{k}_{3}$ \\
\hline
\end{tabular}




\section{Библиографический список}

1. Ильинский И. В. Человеческий капитал общества: методология познания // Известия высших учебных заведений. Технология легкой промышленности. 2011. № 4 (14). С. 153-156.

2. Долан Э.Д. [и др.]. Эффективность и результативность деятельности предприятия // Сучасні Напрямки Розвитку Економіки I Менеджменту На Підприємствах України. 2015. С. 444.

3. Алпатов Г.Е., Дятлов С.А., Критский М.М. Человеческий капитал России на рубеже XXI века 1999.

4. Белоусова Л. А. [и др.]. Человеческий капитал России: выбор моделей развития 2006.

5. Абалкин Л. И. Стратегия социально-экономического развития России // Научные труды Вольного экономического общества России. 2015. № 6 (195). С. 79-93.

6. Сулейманова Л.Ш. Человеческий капитал как фактор европейской экономической интеграции // Вестник ТИСБИ. 2005. № 1. С. 193-197.

7. Климов С.M. Компоненты человеческого капитала // Режим доступа: http:/gtmarket. ru/laboratory/ expertize/2006/1932. - Дата доступа. 2013. (2).

8. Корогодин И.Т., Саломахина Ю.А. Воспроизводственный подход к исследованию качества человеческого капитала // Вестник Воронежского государственного университета. Серия: Экономика и управление. 2014. № 1. С. $80-84$.

9. Юдин Б. Г. Человеческий потенциал как критический ресурс России / Б. Г. Юдин, Directmedia, 2013.

10. Генкин Б. М., Голева Е.В. Принципы организации труда профессорско-преподавательского состава // Известия Санкт-Петербургского государственного экономического университета. 2019. № 2 (116).

11. Гришнова О.А., ТартичнаЛ.С. Экономическая природа и значение категории человеческий капитал // Украина: Аспекты практики. 2003. № 7. С. 33-37.

12. Базилевич В.Д., Ильин В.В. Метафизика экономики: возможность необходимого // Философия хозяйства. 2009. № 6. С. 97-103.

13. Шевчук Л. Т. Человеческий капитал как фактор экономического роста // Вести ИСЗ. 2008. № 1. С. 111.

14. Добрынин А.И., Дятлов С.А., Курпанский С.А. Методология оценки человеческого капитала // Экономика образования. 1999. № 1. С. 9-25.

15. Корчагин Ю.А. Человеческий капитал-основной фактор развития инновационной экономики // Bulletin de l’Académie internationale CONCORDE. 2014. № 1. C. 49-90.

16. Синицына Г.И., Закарашвили В. М. Человеческий капитал как фактор экономического благосостояния 2015. . 62.

17. Щетинин В.П. Человеческий и вещественный капитал: общность и различие // Мировая экономика и международные отношения. 2003. № 8. С. 55-61.

18. Ahmad R. Significance of human capital 2020.

19. Serra $G$. The First Harrod Problem and Human Capital Formation The First Harrod Problem and Human Capital Formation / G. Serra, 2021.

20. Fix B. The rise of human capital theory 2021.

21. Bunting M. Human capital // Accountancy SA. 2013.

22. Maulana A. THE HUMAN CAPITAL / A. Maulana, 2021.

23. Родионов, Д.Г. Методология системного анализа информационной среды / Д. Г. Родионов, Е.А.Конников, О.А. Конникова // Экономические науки. - 2021. - № 196. - С. 160-174._- DOI 10.14451/1.196.160. 